\title{
The building process as a tool towards an all-inclusive school. A Swedish example focusing on children with defined concentration difficulties such as ADHD, autism and Down's syndrome
}

\author{
Catrin Tufvesson · Joel Tufvesson
}

Received: 2 April 2007/ Accepted: 29 September 2008/Published online: 5 November 2008

(C) The Author(s) 2008. This article is published with open access at Springerlink.com

\begin{abstract}
Professionals who take part in the building process have long been concerned with the same environmental factors, e.g. spatial layout, capacity, and function, as well as user demography. Through the knowledge gained on the ways environmental factors affect users of buildings, the need to understand how to handle these factors has grown, due to their influence on the building process. It will be shown how research on the influence of environmental factors found in the school environment can be applied to the building process. The purpose is to increase the accessibility to education through prolonged concentration ability among extra-sensitive children who have defined concentration difficulties such as Autism Spectrum Disorders (autism), Attention Deficit Hyperactivity Disorder (ADHD), and Down's syndrome. This is a direct attempt to implement Swedish legislation (The Swedish Education Act, SFS 1985, p. 1100) regarding children's accessibility to education, including the aims of the Swedish National Action Plan for Disability Policy ("From Patient to Citizen", Swedish Government Bill 1999/2000, p. 79), which is based on the United Nations' Universal Declaration of Human Rights (1948), where it is stated that all children should have equal access to education. The Swedish Work Environment Authority also declares that the work environment, in this case the school, should be adjusted to the physical and psychological needs of the users of the building (The Work Environment Act, AFS 2000, p. 42).
\end{abstract}

Keywords ADHD - All-inclusive - Architecture - Autism - Building process · Children · Concentration · Down's syndrome · Environmental psychology · School environment

\footnotetext{
C. Tufvesson $(\bowtie)$ e-mail: catrin.tufvesson@spsm.se

URL: www.spsm.se

J. Tufvesson

InfoSpace Arkitektur HB, Box 122, 24622 Loddekopinge, Sweden

e-mail: joel.tufvesson@infospace.se

URL: www.infospace.se
}

The Swedish Institute for Special Needs Education, Kinagatan 7, 22100 Malmo, Sweden 


\section{Introduction}

It is stated in the Swedish Educational Act that disabled children should have the same rights of access to education as other children. That is, schools should be accessible for all children, which is the same intention as declared in the UN's Standard Rules on the Equalisation of Opportunities for Persons with Disabilities. ${ }^{1}$ In practice, this includes access to the actual buildings in order to be able to participate in the education, as well as a supportive environment during the time spent in the school environment. The Swedish National Board of Housing, Building and Planning offer recommendations and guidelines on how to handle limited mobility, reduced visual and auditive capacities, and medical limitations in the design and building of schools. ${ }^{2}$ However, accessibility recommendations and guidelines concerning defined concentration difficulties found in the diagnoses ADHD, autism and Down's syndrome are rare and hard to find.

The design features of the school environment become part of meeting the legal requirements for the work environment, i.e. the school, in accordance with the physical and psychological needs of the users of the building. The users of the school are both staff and pupils, according to Swedish legislation, ${ }^{3}$ and the responsibility to meet any legal requirements for the work environment lies with the head of the school. When building a school, or even when rebuilding a school, the municipality is often the property developer and as such is responsible for the building's accessibility-which also is an aspect of the work environment. ${ }^{4}$

The aim is to show how research concerning the influences of environmental factors found in the school environment can be applied in the Swedish building process for the purpose of avoiding disturbing factors affecting the concentration ability among extrasensitive children who have defined concentration difficulties, such as children with autism, ADHD or Down's syndrome. The research is performed in order to increase the accessibility of education for as many children as possible and make advances towards an all-inclusive school. The results presented in this article are part of a research project with the aim of identifying environmental factors in the school environment that affect the children in question, aged 7-12, and their ability to concentrate.

Previous research concerning the environment and its influence on children in general has shown that there are environmental factors - physical, social and individual-which can contribute to longer periods of concentration, and that there are environmental factors that can shorten or even interrupt the concentration period for children (Evans 2006). In the school environment, children's ability to concentrate can be affected by different sound levels (Enmarker and Boman 2004; Lercher et al. 2003; Hygge et al. 2003; Maxwell and Evans 2000). Research has shown that artificial light (Küller 2004; Küller and Laike 1998) and daylight (Küller and Lindsten 1992; Küller 2002) affect children's behaviour and concentration ability. The materials and equipment need to be accessible, especially for children with disabilities (Doctoroff 2001). At school, the number of school children and staff (Kantrowitz and Evans 2004; Legendré 2003), the possibility for movement (Huse 1995), as well as the teaching methods (Strayhorn and Bickel 2002) are other environmental factors influencing the children's way of handling a particular situation. Individual

\footnotetext{
1 UN's General Assembly Resolution A/RES/48/96, 1993.

2 BFS 1993, p. 57-2006, p. 12 BBR and BFS 2003, p. 19 HIN1.

3 The Work Environment Act, AFS 2000, p. 42.

4 Ibid.
} 
factors such as age, gender (Laike 1997; Reese et al. 2005; Lehnung et al. 2003), and disabilities (Faber Taylor et al. 2002), especially concerning children, also have an impact on behaviour. Shibata and Suzuki (2004) found that indoor plants have positive effects on emotional state and creative task performance. Other studies have shown the impact of a view through a window, i.e. that a natural environment could restore and prolong the capacity for concentration (Tennessen and Cimprich 1995; Faber Taylor et al. 2002; Kaplan 2001).

What children with autism, ADHD, and Down's syndrome all have in common is that they have learning and concentration difficulties due to the symptoms of their disabilities (Singhania 2005; Dreschler et al. 2005; Clibbens et al. 2002). They are also extra sensitive to their environment (Reese et al. 2005; Zentall 2005; Cuckle and Wilson 2002). That is, they experience great difficulties in staying focused in an environment with a wide variety of sensory input, which in the case of learning will result in interrupted study activity. They are easily affected by their physical and social environments due to their sensory dysfunction, for example through visual (Deacon et al. 2005), auditory (Rogers and Ozonoff 2005), and emotional influences (Thapar et al. 2006). This has far-reaching effects on their abilities and their well-being (Barber et al. 2005; Bieberich and Morgan 2004; Bauminger et al. 2003) and as such influences their capacity to concentrate at school. Children suffering from ADHD find it difficult to pay attention and control their own reactions, and as a result they are often fidgety and interrupt others (Archibald et al. 2005; Hastings et al. 2005; Brody 2001; Nigg and Casey 2005). Impairments in cognitive, learning, and social skills can occur (Bruce et al. 2006). Autism spectrum disorder affects the functioning of social interaction, social communication, and personal behaviour (Meresse et al. 2005; Singhania 2005; Rinehart et al. 2006). Down's syndrome is a genetic disorder (Nadel 2003; Hedov et al. 2002) that includes delayed motor skills (Lauteslager et al. 1998), delayed cognitive and communicative skills such as speech and language acquisition (Paterson et al. 2006; Boudreau and Chapman 2000), impaired short-term memory (Purser and Jarrold 2005), and learning limitations (Gathercole and Alloway 2006). Due to their symptoms, it is a problem for these children to avoid and ignore environmental input that they experience at school. The children's inability to avoid input from the surrounding environment makes them extra sensitive to the impact of design features in the school.

\section{The Human Environment Interaction model}

In Sweden, newly developed public buildings and premises are designed and built to be accessible to people with limited mobility and diminished visual and auditive capacities. To provide accessibility for the group of people with defined concentration capacities, a model based on theories from Environmental Psychology has been used in an attempt to find guidance for structuring indoor school environments around children with Down's syndrome, autism, and ADHD (Tufvesson 2007). Two studies (Study I and II) involving school professionals have been done on concentration difficulties in the school environment, with an emphasis on children with ADHD, autism, and Down's syndrome. In Study I, 125 personal assistants and teachers working with the children concerned at schools within the Region of Skåne completed a questionnaire. ${ }^{5}$ In Study II, 137 speech and occupational therapists, physiotherapists, psychologists, special pedagogues, medical

\footnotetext{
5 The questionnaires were distributed in September 2004, and the questionnaires were received back over the two following months.
} 
personnel, welfare officers, and recreation instructors from ten Child- and Youth Habilitation Services in the Region of Skåne completed a second questionnaire. ${ }^{6}$

It was decided early on to avoid approaching the children directly. They are hard to question due to the symptoms of their disabilities, such as difficulties with the perception of time and space, communication, and social interaction (Bruce et al. 2006; Singhania 2005; Paterson et al. 2006). There was also a wish not to make changes or conduct experiments in their ordinary environment, since these children have problems ignoring and avoiding physical and social input from their surroundings at school (Gumenyuk et al. 2005; Bebko et al. 2006; Guralnick 2002). A solution to the problem was to approach different categories of professionals working with these children, both at the children's schools and at the Child- and Youth Habilitation Services, with questionnaires.

The questionnaire used in the first study was concerned with the features of the design in the school environment and their negative and positive influences on the length of the concentration time among children with Down's syndrome, autism, and ADHD. In study two, the aim was to validate and complement the results derived from the first study. The influences affecting the children's possibility to concentrate were divided into physical and social factors. The physical ones include the layout of the room, the view through windows, the interior furnishing, noise and light conditions, and so forth. The social factors cover, for instance, the pedagogical atmosphere comprising spatial function, the number of people present, and the teaching method. The individual factors studied were disability, age, and gender (Table 1). The activity evaluated was the children's ability to concentrate during learning situations in their school environment. These factors were expected to interact and influence the children's level of concentration. It was expected that these children would have certain behavioural aspects in common, but it was also expected that differences between the disabilities would be found. ${ }^{7}$

Through the application of the Human Environment Interaction model (the HEI model), it was possible to analyse the environmental factors found in the learning environment as well as their influences, both positive and negative, on the children with ADHD, autism, and Down's syndrome and their ability to concentrate. The theoretical framework of the thesis is based on the HEI model elaborated by Küller (1991, 2004), which assumes that environmental factors influence the emotional status of the child. Environmental factors consist of both physical and social variables, but the emotions are also affected by the choice of activity and mediated through the characteristics of the individual (Fig. 1).

The HEI model is based on a four-step emotional process linked to the neuro-psychological operation of the reticular activation system (Küller 1991; Laike 1995, 1997; Johansson 2006). The model describes four consecutive steps, the first being activation, which is similar to physiological arousal. The second step will elicit orientation, where the child directs attention and concentration to the task. In the second step, the choice of work equipment will be considered by the child, e.g. a computer, pen and paper, video etc., either in company with their personal assistant, their peers, or independently. The work equipment is further evaluated in the third step, according to its efficiency with respect to the current situation. Once the work equipment has been chosen and the assignment has been satisfactorily carried out, the last step, control, will have been attained. The outcome measure of this process is the child's level of concentration. If the initial choice of work equipment proves unsatisfactory to the child, the experience will likely result in a different evaluation the next time a similar situation occurs (Laike 1995; Johansson 2000). The order

\footnotetext{
6 The questionnaires were collected between November 2005 and February 2006.

${ }^{7}$ Further reading concerning the statistical treatment of the data can be found in Tufvesson (2007).
} 


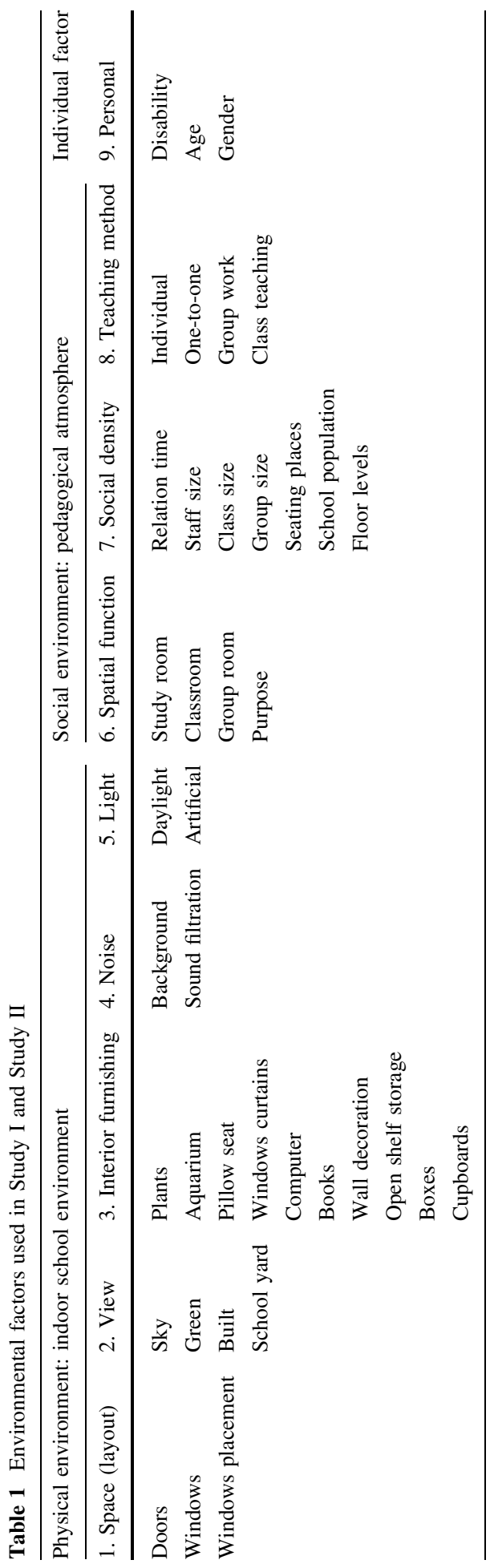




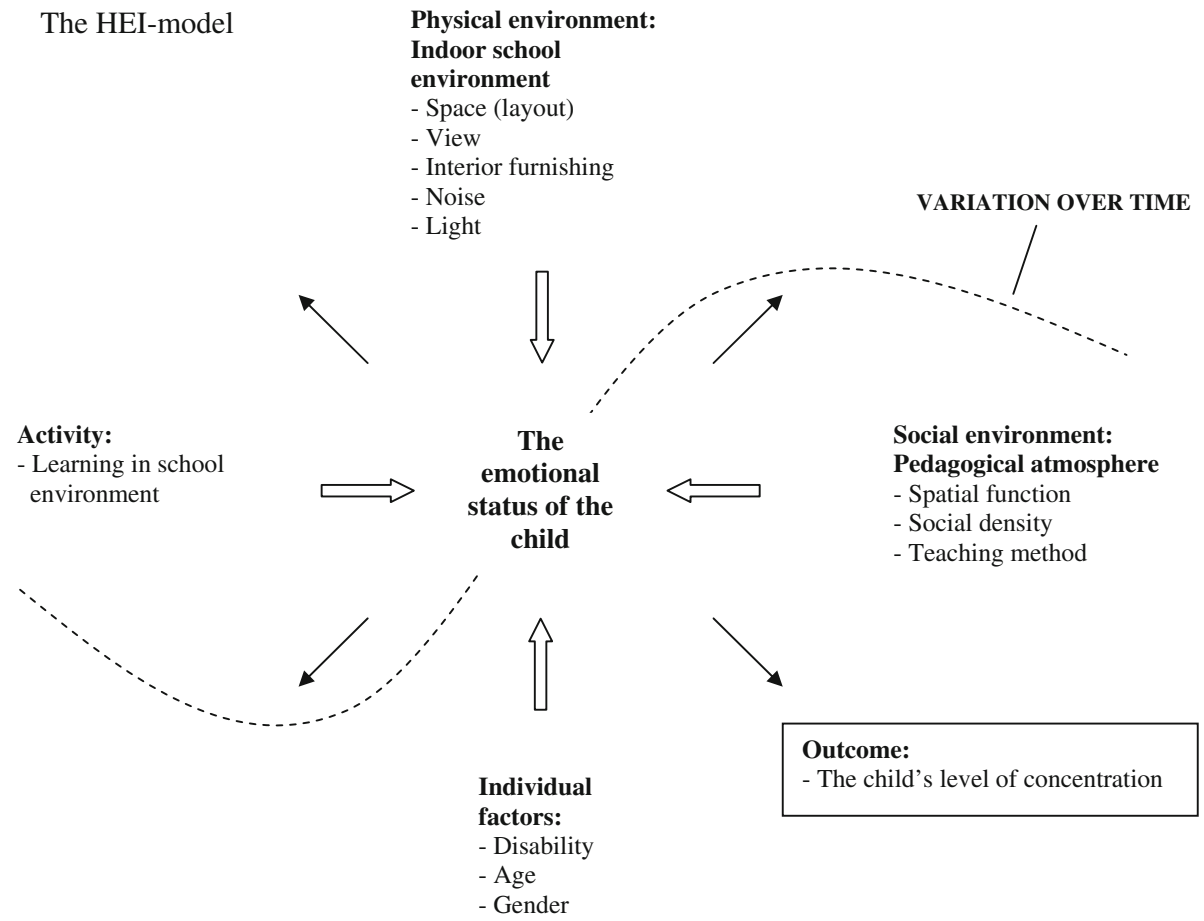

Fig. 1 The Human-Environment-Interaction model shows the interaction between the child and its environment based on a model by Küller (1991)

of the steps in the emotional process will be the same irrespective of the situation. When applying the model to circumstances that influence children's ability to concentrate, the emotional process within the child begins as soon as the child needs to focus on a set assignment (Laike 1997; Johansson 2006).

Laike (1997) describes, in terms of the HEI model and the basic emotional process, how pre-school children's activation during meal situations in groups was due to individual factors, while the social environment influenced orientation, and the social and physical environments influenced the evaluation. The ability to control was dependent on background factors and the situation. The situation being evaluated required concentration in order to achieve a successful outcome, which can be identified as learning in the school setting. However, children with ADHD, autism, and Down's syndrome can be described as having problems completing the orientation and evaluation steps due to the characteristics of their disabilities. That is, their social and physical environments can easily influence them, whereby they often lose their focus and do not reach the level of control. Consequently, these children generally have relatively short periods of concentration.

\section{Results}

A general assumption was that the heightened sensitivity to environmental influences in the studied children would result in a noticeable response to those environmental factors. This assumption has been substantiated in previous research on children in general. 
Environmental factors - physical, social, and individual - were assumed to trigger a break in their concentration period during learning. Physical factors such as the layout of the classroom, background noise, daylight, interior furnishing, and the need for a view would, according to previous research, affect their behaviour. A social factor of importance to children's behaviour is the pedagogical atmosphere, which is a result of a combination of the teaching method, the number of people present in the classroom, and the spatial function. The symptoms connected with the disabilities are individual factors that will influence the children's ability to concentrate; as such, these factors were assumed to shorten the concentration period. There could also be several coexisting environmental factors in the classroom affecting the children's ability to concentrate, both positively and negatively.

So, how should the school environments be designed in order to be all-inclusive for children with defined concentration difficulties who are extra sensitive to the design features in their environment? The results are discussed at three levels in relation to practical applications: (1) an overall level, where general principles concerning all of the disabilities could be found; (2) a specific level, where principles concerning the different disabilities could be found; and (3) an individual level, where individual needs could be provided for. In addition, the demand for pre-project discussions in the building process were considered, as were certain results such as the influence of the view on the children's ability to concentrate, and the requirement of having school environments designed to serve the needs of the children.

\subsection{General influences at an overall level}

The results from the two studies showed that environmental factors influenced these children and their ability to concentrate, a finding consistent with previous research on the concentration ability of children in general. This finding would have implications for the features of the school environment and thus would need to be taken into account when designing schools for children in general as well for as children with defined concentration difficulties. The following factors were perceived to have a negative influence on the children in question and their ability to concentrate negatively; these are the same factors found by previous researchers to have a negative influence on children's concentration in general. Background noise and sound filtration had a negative impact; this was confirmed by Enmarker and Boman (2004) to negatively affect children. Lower levels of noise increased children's ability to concentrate, as shown by Norlander et al. (2005). Direct daylight on the work place interrupted every second child's concentration. Similarly, too much daylight was shown by Wilson (2004) to worsen students' performance. Consistent with the results of Kantrowitz and Evans (2004), Legendré (2003), Schneider (2002), and Moore and Lackney (1993), having a high number of students and staff nearby could influence children's behaviour negatively. Class teaching was shown by Strayhorn and Bickel (2002) to be a negative teaching method in relation to concentration; this was also found to be the case for the children in question. The actual disability in itself was perceived to have a negative influence on the children's ability to concentrate, which was also interpreted as a negative influence by Faber Taylor et al. (2002). An environmental factor perceived by the respondents to have a positive influence on all of the children and their ability to concentrate was one-to-one teaching, which the research by Bronson et al. (1997) also showed. Further environmental factors, such as several doors, and window placement on several walls, were also perceived by the respondents in the research project 
to have a negative effect on all of the children's ability to concentrate; to the authors' knowledge these factors have not been studied before.

Other general influences on the children's ability to concentrate were classroom settings, as shown by Martin (2002). These were perceived to be of major importance for the children in question, who needed to do individual work at purpose-suited places or personal seating places in order to function well, a perception also supported by the work of Adams et al. (2000). A smaller room such as a group room where group work could be organised was considered to be positive. But as the studies by Charlop et al. (1983), Pavuluri et al. (1999), Cuckle and Wilson (2002), and Singhania (2005) also show, group work was considered as time consuming and difficult to pursue. According to Doctoroff (2001), the materials and equipment necessary for a learning task need to be accessible, which in this case means they could support these children successfully through the whole of the basic emotional process (Laike 1997). However, it was perceived by the respondents that materials and equipment not used for the moment needed to be stored in closed storage systems such as cupboards and drawers, and not in open shelf storage.

\subsection{Specific influences concerning specific disabilities}

Three rooms were composed that would be likely to support the children's perceived ability to concentrate. The rooms were set up in accordance with the results from Study I, in which personal assistants and teachers gave their point of view, together with the results from Study II, where professionals working at the Child and Youth Habilitation Services gave their perceptions. However, environmental factors perceived by the respondents to be non-supportive were also presented in order to increase the possibility for learning through the avoidance of those factors. Only those factors that showed statistically significant results were considered.

\subsection{A room for learning intended for children with Down's syndrome}

In a room designed for the purpose of learning and intended for children with Down's syndrome, several doors were regarded to have a negative influence on their ability to concentrate, and so was the placement of windows on several walls. However, the placement of several windows on one wall was regarded as having a positive influence. The view through the windows should contain the sky, definitely not the schoolyard, and the issue of greenery was inconsistent. It was also regarded that the children with Down's syndrome should not be without a view when learning. Loose interior furnishings, such as a pillow seat and a computer, were regarded to have positive influences on their ability to concentrate (Table 2).

Storage systems such as open-shelf storage were regarded to have negative influences on the children's ability to concentrate, which was substantiated by the perception of the positive influences from a closed storage system. Sounds filtrating into the room, indoor plants near the working place, as well as direct daylight on the child's work place were regarded to have a negative influence. Smaller rooms such as group rooms were considered to have a positive influence on the children's ability to concentrate. Individual work, a seating place that could be regarded as the child's own place, and purpose-suited places, were other environmental factors perceived as positive. Schools with a high number of pupils were regarded as having a negative influence, and a greater amount of staff was also perceived to shorten the period of concentration among the children. Large rooms such as regular classrooms, with class teaching, were also regarded as having a negative influence 
Table 2 Results from Study I and Study II: regarding influences on the concentration ability for the three groups of disabilities in the School due to environmental and individual factors

\begin{tabular}{|c|c|c|c|c|c|c|}
\hline \multirow[t]{2}{*}{ Study } & \multicolumn{2}{|l|}{ DS } & \multicolumn{2}{|c|}{ Autism } & \multicolumn{2}{|c|}{ ADHD } \\
\hline & $\begin{array}{l}1 \\
\text { P.A. }\end{array}$ & $\begin{array}{l}2 \\
\text { Prof. Hab. }\end{array}$ & $\begin{array}{l}1 \\
\text { P.A. }\end{array}$ & $\begin{array}{l}2 \\
\text { Prof. Hab. }\end{array}$ & $\begin{array}{l}1 \\
\text { P.A. }\end{array}$ & $\begin{array}{l}2 \\
\text { Prof. Hab. }\end{array}$ \\
\hline
\end{tabular}

1. Physical factor: space (layout)

Several doors

Several windows

Window placement on one wall

Window placement on several walls

2. Physical factor: view

Sky

Green

Built

School yard

No view

3. Physical factor: interior furnishing

Plants

Aquarium

Pillow seat

Window curtains

Computer

Wall decoration

Open shelf storage

Boxes

Cupboards/drawers

4. Physical factor: noise

Background

Sound filtration

5. Physical factor: light

Daylight

6. Social factor: spatial function

Study room

Classroom

Group room

Purposely-suited place

7. Social factor: social density

Staff

Seating place

School population

Floor levels

$+\quad+$

$-\quad+$

Social factor: teaching method

Individual work

One-to-one teaching

$\begin{array}{ll} & - \\ + & \\ + & + \\ & - \\ & \\ + & + \\ - & +\end{array}$

\begin{tabular}{|c|c|c|c|c|c|}
\hline & - & & - & & - \\
\hline & - & + & & & \\
\hline- & & & & & \\
\hline & & - & & & \\
\hline & + & + & & & \\
\hline & & + & & & \\
\hline+ & + & - & & - & - \\
\hline & & & - & & - \\
\hline & - & & - & & - \\
\hline & - & & - & + & - \\
\hline+ & + & + & + & + & + \\
\hline- & - & - & - & - & - \\
\hline & - & & - & & - \\
\hline- & & - & & - & \\
\hline+ & & & & & \\
\hline & - & & - & & - \\
\hline & + & & + & & + \\
\hline+ & & + & & + & \\
\hline- & & & & - & \\
\hline+ & & + & & + & \\
\hline & - & + & - & & - \\
\hline & & & & + & \\
\hline+ & & + & & + & \\
\hline+ & + & + & + & + & + \\
\hline
\end{tabular}


Table 2 continued

\begin{tabular}{|c|c|c|c|c|c|c|}
\hline \multirow[t]{2}{*}{ Study } & \multicolumn{2}{|l|}{ DS } & \multicolumn{2}{|c|}{ Autism } & \multicolumn{2}{|c|}{ ADHD } \\
\hline & $\begin{array}{l}1 \\
\text { P.A. }\end{array}$ & $\begin{array}{l}2 \\
\text { Prof. Hab. }\end{array}$ & $\begin{array}{l}1 \\
\text { P.A. }\end{array}$ & $\begin{array}{l}2 \\
\text { Prof. Hab. }\end{array}$ & $\begin{array}{l}1 \\
\text { P.A. }\end{array}$ & $\begin{array}{l}2 \\
\text { Prof. Hab. }\end{array}$ \\
\hline Class teaching & & - & & - & & - \\
\hline Group work & & + & & - & & - \\
\hline \multicolumn{7}{|c|}{ 9. Individual factor: personal } \\
\hline Disability & & - & & - & & - \\
\hline
\end{tabular}

+ , regarded by the respondents to have a positive effect on the children's ability to concentrate

- , regarded by the respondents to have a negative effect on the children's ability to concentrate

P.A., Personal assistants or teachers working with the children in their classroom

Prof. Hab., Professionals working at Child and Youth Habilitation Services meeting the children in their classrooms and at the Habilitation

on their ability to concentrate. In contrast, a study hall, which is usually a large room, was considered to have a positive influence. However, in a study hall, positive environmental factors such as group work, individual work, and a place of their own could be implemented and thus turn the study hall into a positive influence (Table 2).

There were environmental factors that the respondents in both Study I and Study II pointed out to be of importance for the children's ability to concentrate. For children with Down's syndrome, it was placement of windows on one wall, closed storage systems such as cupboards and drawers, and one-to-one teaching which were regarded as having a positive influence on their ability to concentrate, while background noise was regarded to have a negative influence (Table 2).

\subsection{A room for learning intended for children with autism}

The respondents felt that a room for learning intended for children with autism should not contain environmental factors such as several doors. The respondents also felt that children with autism would benefit from not having a view during learning, which is confirmed by the perceived negative influence of windows placed on several walls. This contradicts the perceived positive influence of having several windows, but the contradiction can be explained by the children's diverse ways of being able to handle views due to their disability. This contradiction also concerns the different influences of schools with large populations; while some children could handle larger populations, others were more comfortable in schools with smaller populations (Table 2).

A view of the schoolyard was regarded as having a negative influence on the children's ability to concentrate, and so was direct daylight on the children's work place. Loose interior furnishings such as curtains and a pillow seat were regarded as having a positive influence on the children, whereas computers and wall decorations were regarded to be negative influences. Open-shelf storage and loose boxes were regarded as negative influences; this was confirmed by the positive influence felt to come from closed storage systems such as cupboards and drawers. Other negative environmental factors influencing the children's ability to concentrate, as perceived by the respondents, were background noise and sound filtrated into the room. Individual work, a personal seating place, a purpose-suited place, and one-to-one teaching were all regarded to have positive influences on the children. A smaller room such as a group room was positive, even if group work was 
regarded as negative, and both a classroom and class teaching were regarded as negative (Table 2).

Environmental factors such as closed storage and one-to one teaching were perceived by the respondents in both Study I and Study II to have a positive influence on children with autism and on their possibility to concentrate, while background noise was perceived as a negative influence (Table 2).

\subsection{A room for learning intended for children with ADHD}

A room for learning intended for children with ADHD should have neither several doors nor several windows. To have windows placed on several walls was regarded as a negative influence on the children and their ability to concentrate. There was a contradiction regarding the perception of loose boxes, the population size of the school, and the number of floor levels. This can be explained by the fact that there were some children who could handle these environmental factors and a group of children who could not handle them, possibly due to the wide spectrum of concentration difficulties within the disability (Table 2).

To have a view of the schoolyard and to have direct daylight on the work place were regarded as having a negative influence on the children's ability to concentrate. Loose interior furnishings such as wall decorations had a negative influence on the children. Open-shelf storage was felt to have a negative effect on the children, which could be confirmed by the respondents' perception of a positive influence from closed storage such as cupboards and drawers. Background noise and sound filtration were also felt to have negative effects on the children. A smaller room such as a group room was regarded as positive for the children, even if group work was regarded as negative. Both a classroom and class teaching were regarded as negative, and a higher amount of staff was perceived to shorten the period of concentration among the children. The presence of several computers was also considered to have a negative influence. A personal seating place, individual work, a purpose-suited place, and one-to-one teaching were all regarded to have positive influences on the children's ability to concentrate (Table 2).

The respondents in Study I as well as in Study II, perceived environmental factors such as closed storage and one-to-one teaching as influencing children with ADHD and their ability to concentrate in a positive way, while background noise was perceived as having a negative influence (Table 2).

\subsection{Implementation in the building process}

Today's school environments have to be designed to be all-inclusive. This applies especially to newly built structures, but also to the maintenance of existing school environments. This raises the issue of implementation-how to bring the differing needs of children with ADHD, autism, and Down's syndrome into the building process. It was suggested by the authors that if a pre-project decision phase was attached and incorporated into the cyclic building process (Carenholm 2002), the environmental factors found to be relevant could be applied to support the ability to concentrate among these children and would thereby increase their accessibility to education. The participants (politicians and employees within the municipality, project managers, consultants, user organisations, and facility management) tied to school projects in accordance with the cyclic building process have the potential to implement this new knowledge. 
The professionals within the building process have addressed the same environmental factors for a long time: e.g. the spatial layout, capacity and function, and user demography. These are the same environmental factors that were shown to influence the concentration ability among children with ADHD, autism, and Down's syndrome.

\subsection{The cyclic building process}

The traditional model of the building process describes it as linear and phased, consisting of four different phases: the design, preparation, construction, and facility processes. The user organisation provides input at the different stages of the design process (Fig. 2).

The cyclic model of the building process has the same phase content as the linear model (Fig. 3a). The main difference between the two models is that the linear model of the building process describes the phases and their parts as isolated elements and does not take any account of the project information flow (Carenholm 2002). The feedback loops between the different phases shown in the cyclic model of the building process, as well as the participation and follow-up procedures, made it possible to include the environmental factors affecting the concentration ability among the children in question. The feedback consists of previously gained knowledge and experience from the different participants. The cyclic model of the building process proved useful as a starting point, though other models exist, for a further discussion of implementing significant environmental factors for the sake of increasing the access to education among these children.

The cyclic model of the building process is founded on the acquisition of knowledge between the phases and their parts, i.e. between the facility and design processes, the facility and preparation processes, and the construction and preparation processes. These flows of information have always existed. But as the demand for efficient project organisation and an efficient use of resources has increased, as have the user organisations' rights to joint consultation, the need for formalised information flows has grown accordingly. In order to ensure that the environmental factors that are relevant for the children in question are included, they need to be addressed at a pre-project decision stage (Fig. 3b) and incorporated into the cyclic building process.

During pre-project decisions, questions regarding the pedagogical atmosphere, school size, building orientation, and outdoor acoustics ${ }^{8}$ should be raised and considered before the first phase of the actual building process begins (environmental factors no. 1-4a in Fig. 3b), which is where they are to be resolved. At present, the aspects that affect concentration ability among extra-sensitive children have had limited impact on these discussions. This is due to the lack of previous knowledge but also to the fact that these issues often have been addressed outside of the formal building process in an earlier context-in a school-planning context that has usually been political. By linking the preproject decision stage with the building process, better conditions for building schools supportive to children with ADHD, autism, and Down's syndrome could be achieved.

\subsection{The pre-project discussions}

In the pre-project discussions, several parties are needed in order to implement previous knowledge and gained information. The property developer-in most cases regarding schools, this is the municipality - is the liable party and as such responsible for making sure that the school buildings meet accessibility demands. Its representatives are normally

${ }^{8}$ Outdoor acoustics is in this case outdoor sounds that affect the indoor acoustic climate. 


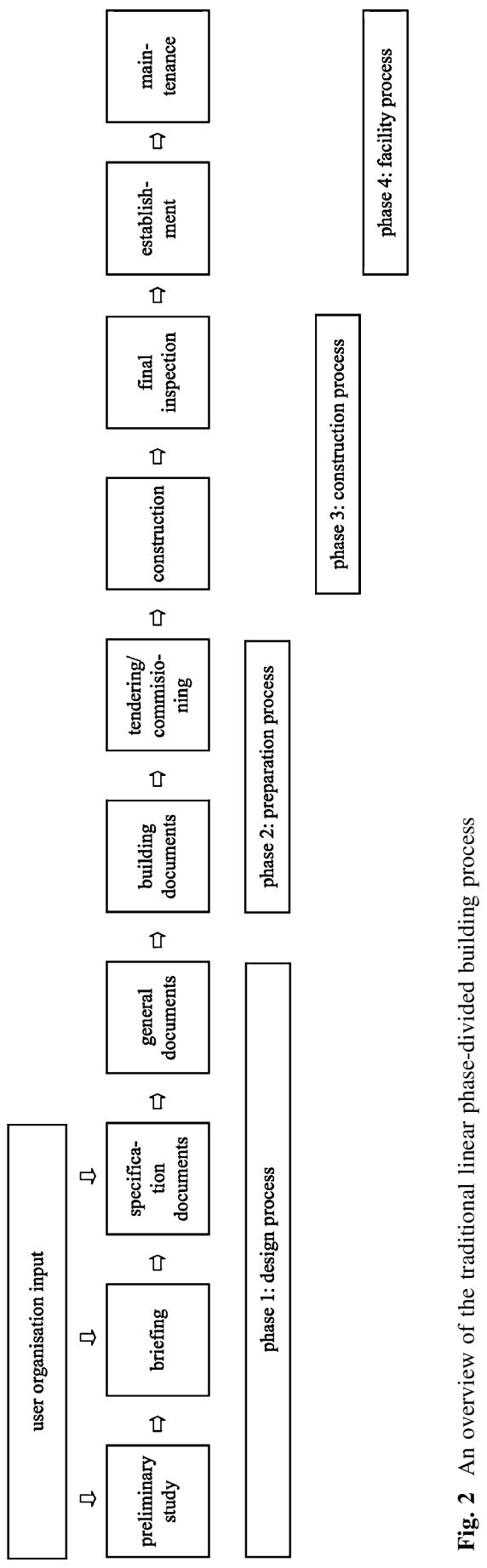


(a)
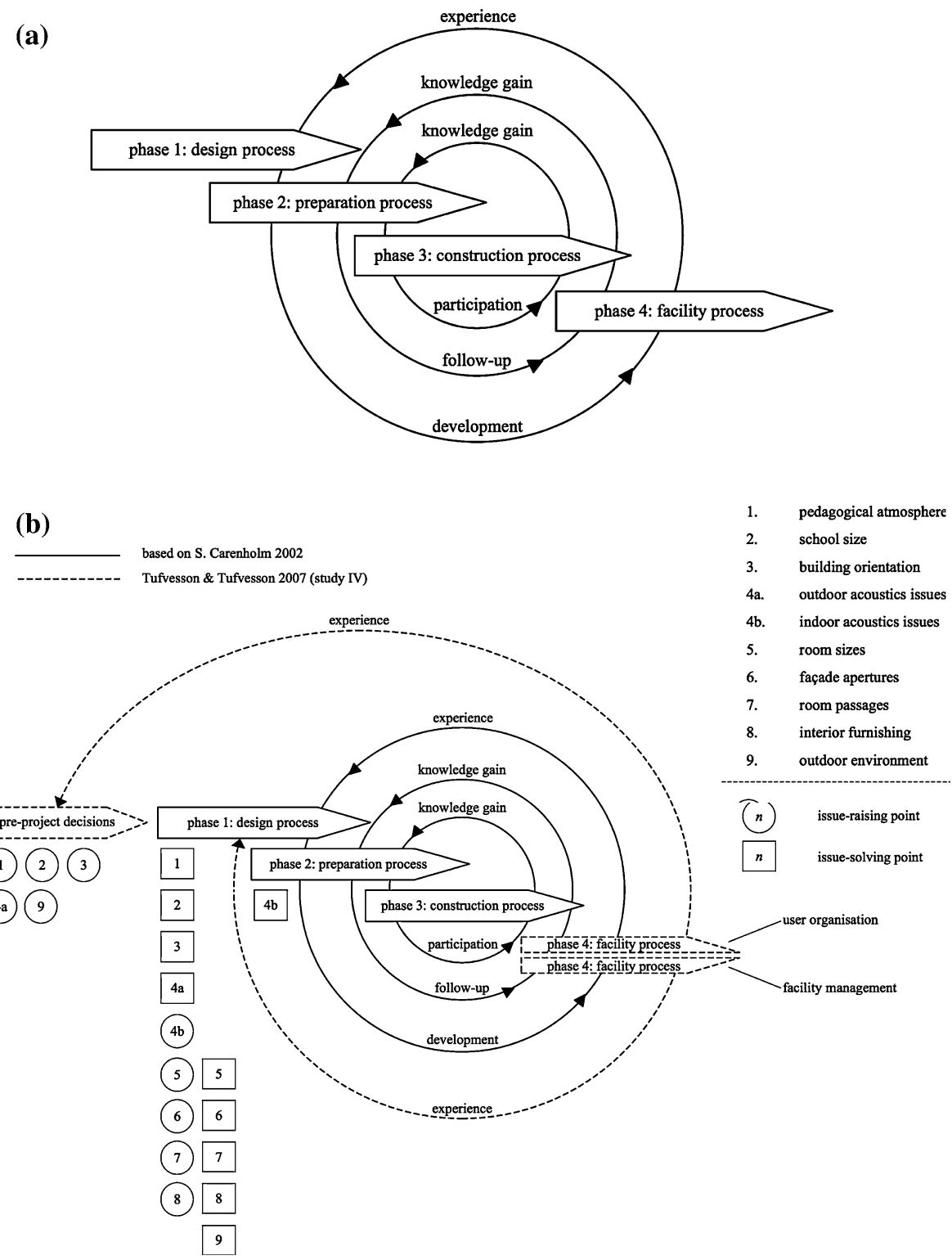

Fig. 3 a The cyclic building process, Carenholm (2002, p. 55). Reprinted with author's consent. b The cyclic building process with respect to children with defined concentration difficulties

publicly elected politicians and municipal employees. The project manager co-ordinates the necessary expertise required for the project, and the consultants provide the knowledge to meet the specifications of the building.

The user organisation, the actual user of the school building, represents the hands-on experience concerning the different needs, which depend on the disabilities and the individuals. As such, this organisation can provide vital information concerning the selection 
of teaching methods and the pupils' need for environmental support. The experience from the facility management should also be included to ensure that future facility management does not come into conflict with the intentions stated in the project plan, i.e. the aim to support concentration among children with ADHD, autism, and Down's syndrome. If these participants are all engaged in the pre-project discussions, the intention to implement previous experience and gained knowledge shown in the cyclic model of the building process could be achieved.

The same arguments could be applied to the treatment of issues regarding pedagogical atmosphere, school size, building orientation, and outdoor acoustics, as well as to interior furnishing. Therefore, the interiors should also be included in the building process, more specifically in the design process (phase 1). The interior furnishing in a school project is often treated as a side-contract, commissioned by the school administration or corresponding body, and therefore falls outside the building process. However, the interior furnishing should be treated as equally important as e.g. the placement of windows, doors etc., since the ability to concentrate has proven to be affected by the overall spatial impression. Further issues such as the indoor acoustics, room size, façade apertures, room passages, and outdoor environment ${ }^{9}$ (environmental factors no. 4b-9 in Fig. 3b) should also be raised and resolved within phase 1, the design process. The outdoor environment is also one of those factors that are usually resolved outside the building process at a later stage. Considering the importance of the view for the children's ability to concentrate, this matter ought to be treated actively during the building process. Indoor acoustics are usually resolved within phase 2 , the preparation process.

The point in the building process where the environmental factors are to be implemented is important, but so is the selection of the participants who will address them. The proposed implementations of the environmental factors in the cyclic building process need to be considered by the property developer, represented by politicians and municipality employees, together with the project manager, consultants, the user organisation, and the facility management in order to increase the accessibility in school environments for cognitively limited children. All the participants connected to the cyclic building process have an important role to play in order to make education accessible for all children. ${ }^{10}$

\section{Discussion}

Accessibility becomes an issue in the effort to implement the national aims formulated in Sweden for an all-inclusive school. So far the Swedish National Board of Housing, Building and Planning have offered recommendations and guidelines on how to handle limited mobility, reduced visual and auditive capacities, and medical limitations in the design and building of schools. Through implementing the knowledge concerning the influences deriving from environmental factors and affecting children with defined concentration difficulties, the school would become more widely accessible. The increased support developed in the surrounding environment would make education even more accessible due to the children's increased possibilities for learning.

The need for individual arrangements made by the pedagogues through implementing different seating arrangements, personal assistants or pedagogues, making the view

\footnotetext{
9 The design of the outdoor environment should follow the building process.

${ }^{10}$ Swedish Government Bill 1999/2000, p. 79, and UN's General Assembly Resolution A/RES/48/96, 1993.
} 
accessible or not, and choosing interior furnishings such as the storage system should be considered during the building process. These environmental factors have a flexible character and as such could make the learning environment more supportive of a child's individual needs. Should there be more flexibility? Adjustments are often made due to the built-in features of the environment, i.e. openings such as doors and windows, the movement and noise of other children, and the size of the classrooms. However, the need for flexibility in the allocation of the children in question within the school buildings ought to be considered in accordance with their environmental needs. In existing school buildings the possibility to cater for all needs is by definition limited. But in new-built structures, the prerequisite knowledge could be implemented in order to make informed decisions regarding flexibility and specific qualities of the buildings in relation to special needs.

Accessibility of school environments for children with defined concentration difficulties depends on environmental factors, as has been shown, and these factors are regulated through the project documentation and the management of the building. Usually, the property developer assigns a project manager to locate the required knowledge for solving accessibility issues, commonly an architect or an accessibility consultant.

However, caution has to be taken when identifying and adding/subtracting environmental factors in the school environment, with respect to the purpose of making education accessible to all children, due to synergetic effects between environmental factors and the disabilities in question (Tufvesson 2007). This synergy makes every situation unique and requires an analysis of the different combinations of factors present in the actual building project (Gathorne-Hardy 2001). The analyses require skill and experience, including knowledge concerning the different environmental factors and how they influence people and their behaviour, in order to make an environment such as a school more accessible (Janssens and Laike 2006, p. 16). During the design and preparation processes, it is normally the architect who has the most experience and skill in this type of work, and in theory, it is through the architectural building documentation that these issues ought to be addressed.

In practice there are two aspects to be considered in the building process in order to increase the accessibility of the school. Firstly, in order to address these issues with respect to the design of the school environment, expert knowledge is required. Secondly, it should be acknowledged that every space is unique and involves different conditions depending on the project content, design, character, etc. Therefore, in each school project there is a need for specific data for decision-making during the pre-project decision stage, the design and preparation processes (phase 1, in Fig. 2). We believe that supportive school environments for all children can be achieved through a development of the cyclic building process as shown in Fig. 3b.

The implication of some of the results has been considered in more detail with respect to its interpretation and application. First, the results concerning the view through windows showed that different contents of the views influenced the children's ability to concentrate differently, as did the actual access (Wilson 2004), or a lack of access, to views through windows in school classrooms. If the results of this investigation had supported previous research findings that a view containing a natural environment could restore and prolong the capacity for concentration (Kaplan 2001), it would have been a pleasant element in the schoolyard and one that could be arranged in pre-existing school environments. However, the results implied taking more complex demands into account regarding the location of the school building, the façade apertures, and the design of outdoor environments in order to improve the children's performance. 
Secondly, the limitations of the suggested implementations need to be considered, especially since the discussion is focused on the Swedish building process. The approach to the problem could also be discussed, but the suggestions given here are an attempt to implement national and international legislation in order to increase accessibility of education to all children through increased access to the school. The discussion ought to be applicable on a conceptual level to other building cultures, though it should be kept in mind that environmental factors can have a different influence depending on cultural, geographical, and technical aspects. The symptoms of the disabilities will, however, be the same.

Further research is needed into orientation disabilities other than the ones discussed in this article. At the same time, there is a need for more detailed knowledge on the complexity and the synergetic effects of the influences from the environmental factors. The application of the knowledge in the building process should also be developed further with respect to other building cultures in order to increase the accessibility of education for all children.

Acknowledgements The authors are grateful for comments made by Dr. Thorbjörn Laike and Dr. Maria Johansson, Environmental Psychology, Department of Architecture and Built Environment, Lund University, Sweden.

Open Access This article is distributed under the terms of the Creative Commons Attribution Noncommercial License which permits any noncommercial use, distribution, and reproduction in any medium, provided the original author(s) and source are credited.

\section{References}

Adams, J., Swain, J., \& Clark, J. (2000). What's so special? Teachers' models and their realisation in practice in segregated schools. Disability and Society, 15(2), 233-245.

Archibald, S. J., Kerns, K. A., Mateer, C. A., \& Ismay, L. (2005). Evidence of utilization behavior in children with ADHD. Journal of the International Neuropsychological Society, 11, 367-375.

Barber, S., Grubbs, L., \& Cottrell, B. (2005). Self-perception in children with attention deficit/hyperactivity disorder. Journal of Pediatric Nursing, 20(4), 235-245.

Bauminger, N., Shulman, C., \& Agam, G. (2003). Peer intervention and loneliness in high-functioning children with autism. Journal of Autism and Developmental Disorders, 33(5), 489-507.

Bebko, J. M., Weiss, J. A., Demark, J. L., \& Gomez, P. (2006). Discrimination of temporal synchrony in intermodal events by children with autism and children with developmental disabilities without autism. Journal of Child Psychology and Psychiatry, 47(1), 88-98.

Bieberich, A. A., \& Morgan, S. B. (2004). Self-regulation and affective expression during play in children with autism or Down syndrome: A short-term longitudinal study. Journal of Autism and Developmental Disorders, 34(4), 439-448.

Boudreau, D. M., \& Chapman, R. S. (2000). The relationship between event representation and linguistic skill in narratives of children and adolescents with Down syndrome. Journal of Speech, Language and Hearing, 43, 1146-1159.

Brody, J. F. (2001). Evolutionary recasting: ADHD, mania and its variants. Journal of Affective Disorders, $65,197-215$.

Bronson, M. B., Hauser-Cram, P., \& Erickson Warfield, M. (1997). Classroom matter: Relations between the classroom environment and the social and mastery behavior of five-years-old children with disabilities. Journal of Applied Developmental Psychology, 18, 331-348.

Bruce, B., Thernlund, G., \& Nettelbladt, U. (2006). ADHD and language impairment. A study of the parent questionnaire FTF (Five to Fifteen). European Child Adolescent Psychiatry, 15, 52-60.

Carenholm, S. (2002). Arkitektföretaget [Architecture company]. Sweden: Sveriges Arkitekter Arkitektservice $\mathrm{AB}$.

Charlop, M. H., Schreibman, L., Mason, J., \& Vesey, W. (1983). Behavior-setting interactions of autistic children: A behavioral mapping approach to assessing classroom behaviors. Analyses and Intervention in Developmental Disabilities, 3, 359-373. 
Clibbens, J., Powell, G. G., \& Atkinson, E. (2002). Strategies for achieving joint attention when signing to children with Down's syndrome. International Journal of Language and Communication Disorders, 37(3), 309-323.

Cuckle, P., \& Wilson, J. (2002). Social relationships and friendships among young people with Down's syndrome in secondary schools. British Journal of Special Education, 29(2), 66-71.

Deacon, M. A., Woodhouse, J. M., \& Watts, P. O. (2005). Investigation of ocular alignment and binocular single vision in children with Down's syndrome. International Congress Series, 1282, 88-92.

Doctoroff, S. (2001). Adapting the physical environment to meet the needs of all young children for play. Early Childhood Education Journal, 29(2), 105-109.

Dreschler, R., Brandeis, D., Földényi, M., Imhof, K., \& Steinhausen, H. (2005). The course of neuropsychological functions in children with attention deficit hyperactivity disorder from late childhood to early adolescence. Journal of Child Psychology and Psychiatry, 46(8), 824-836.

Enmarker, I., \& Boman, E. (2004). Noise annoyance responses of middle school pupils and teachers. Journal of Environmental Psychology, 24, 527-536.

Evans, G. W. (2006). Child development and the physical environment. Annual Review of Psychology, 57, 423-451.

Faber Taylor, A., Kuo, F., \& Sullivan, W. C. (2002). Views of nature and self-discipline: Evidence from inner city children. Journal of Environmental Psychology, 22, 49-63.

Gathercole, S. E., \& Alloway, T. P. (2006). Practitioner review: Short-term and working memory impairments in neurodevelopmental disorders: Diagnosis and remedial support. Journal of Child Psychology and Psychiatry, 47(1), 4-15.

Gathorne-Hardy, F. (2001). Inclusive design in schools. Support for Learning, 16(2), 53-55.

Gumenyuk, V., Korzyukov, O., Escera, C., Hämäläinen, M., Huotilainen, M., Häyrinen, T., et al. (2005). Electrophysiological evidence of enhanced distractibility in ADHD children. Neuroscience Letters, $374,212-217$.

Guralnick, M. J. (2002). Involvement with peers: Comparisons between young children with and without Down's syndrome. Journal of Intellectual Disability Research, 46(part 5), 379-393.

Hastings, R. P., Beck, A., Daley, D., \& Hill, C. (2005). Symptoms of ADHD and their correlates in children with intellectual disabilities. Research in Developmental Disabilities, 26, 456-468.

Hedov, G., Annéren, G., \& Wikblad, K. (2002). Swedish parents of children with Down's syndrome. Scandinavian Journal of Caring Science, 16, 424-430.

Huse, D. (1995). Restructuring and the physical context: Designing learning environments. Children, Youth and Environments, 12(3), 10-42.

Hygge, S., Boman, E., \& Enmarker, I. (2003). The effects of road traffic noise and meaningful irrelevant speech on different memory systems. Scandinavian Journal of Psychology, 44, 13-21.

Janssens, J., \& Laike, T. (2006). Rum för återanpassning (Spaces for rehabilitation). Statens Institutions Styrelse, SIS 2/06.

Johansson, M. (2000). Psychological motivation of pro-environmental travel behaviour in an urban area. In T. Rothengatter \& R. D. Huguenin (Eds.), Traffic and transport psychology (pp. 435-442). Amsterdam: Elsevier.

Johansson, M. (2006). Environment and parental factors as determinants of mode for children's leisure travel. Journal of Environmental Psychology, 26(2), 156-169.

Kantrowitz, E. J., \& Evans, G. W. (2004). The relation between the ratio of children per activity area and off-task behavior and type of play in day care centers. Environment and Behavior, 36(4), 541-557.

Kaplan, R. (2001). The nature of the view from home. Environment and Behavior, 33(4), 507-542.

Küller, R. (1991). Environmental assessment from a neuropsychological perspective. In T. Gärling \& G. W. Evans (Eds.), Environment, cognition and action: An integrated approach. New York: Oxford University Press.

Küller, R. (2002). The influence of light on circarhythms in humans. Journal of Physiological Anthropology and Applied Human Science, 21(2), 87-91.

Küller, R. (2004). Planning for good indoor lighting. Building Issues, 14. Lund: SIDA and HDM.

Küller, R., \& Laike, T. (1998). The impact flicker from fluorescent lighting on well-being, performance and physiological arousal. Ergonomics, 41(4), 433-447.

Küller, R., \& Lindsten, C. (1992). Health and behavior of children in classrooms with and without windows. Journal of Environmental Psychology, 12, 305-317.

Laike, T. (1995). Observing the emotional state of healthy children. Children's Environments, 12(3), 328339.

Laike, T. (1997). The impact of daycare environments on children's mood and behavior. Scandinavian Journal of Psychology, 38, 209-218. 
Lauteslager, P. E. M., Vermeer, A., \& Helders, P. J. M. (1998). Disturbances in the motor behavior of children with Down's syndrome: The need for a theoretical framework. Physiotherapy, 84(1), 5-13.

Legendré, A. (2003). Environmental features influencing toddlers' biomotional reactions in day care centres. Environment and Behavior, 35(4), 523-549.

Lehnung, M., Leplow, B., Oksendal, H., Vegard, M. M., \& Ferstl, R. (2003). Pointing accuracy in children is dependent on age, sex and experience. Journal of Environmental Psychology, 23, 419-425.

Lercher, P., Evans, G. W., \& Meis, M. (2003). Ambient noise and cognitive processes among primary schoolchildren. Environment and Behavior, 35(6), 725-735.

Martin, S. H. (2002). The classroom environment and its effects on the practice of teachers. Journal of Environmental Psychology, 22, 139-156.

Maxwell, L. E., \& Evans, G. W. (2000). The effects of noise on pre-school children's pre-reading skills. Journal of Environmental Psychology, 20, 91-97.

Meresse, I. G., Zilbovicius, M., Boddaert, N., Phillippe, A., Laurier, L., Samson, Y., et al. (2005). Autism severity and temporal lobe functional abnormalities. American Neurological Association, 58, 466-469.

Moore, G. T., \& Lackney, J. A. (1993). School design: Crisis, educational performance and design applications. Children's Environments, 10(2), 99-112.

Nadel, L. (2003). Down's syndrome: A genetic disorder in biobehavioral perspective. Genes, Brain and Behavior, 2, 156-166.

Nigg, J. T., \& Casey, B. J. (2005). An integrative theory of attention-deficit/hyperactivity disorder based on the cognitive and affective neurosciences. Development and Psychopathology, 17, 785-806.

Norlander, T., Moås, L., \& Archer, T. (2005). Noise and stress in primary and secondary school children: Noise reduction and increased concentration ability through a short but regular exercise and relaxation program. School Effectiveness and School Improvement, 16(1), 91-99.

Paterson, S. J., Girelli, L., Butterworth, B., \& Karmiloff-Smith, A. (2006). Are numerical impairments syndrome specific? Evidence from Williams syndrome and Down's syndrome. Journal of Child Psychology and Psychiatry, 47(2), 190-204.

Pavuluri, M. N., Luk, S.-L., \& McGee, R. (1999). Parent reported preschool attention deficit hyperactivity: Measurement and validity. European Child and Adolescent Psychiatry, 8, 123-133.

Purser, H. R. M., \& Jarrold, C. (2005). Impaired verbal short-term memory in Down syndrome reflects a capacity limitation rather than a typically rapid forgetting. Journal of Environmental Child Psychology, 91, 1-23.

Reese, R. M., Richman, D. M., Belmont, J. M., \& Morse, P. (2005). Functional characteristics of disruptive behavior in developmental disabled children with and without autism. Journal of Autism and Developmental Disorders, 35(4), 419-427.

Rinehart, N. J., Bradshaw, J. L., Moss, S. A., Brereton, A. V., \& Tonge, B. J. (2006). Pseudo-random number generation in children with high-functioning autism and Asperger's disorder. Autism, 10(1), $70-85$.

Rogers, S. J., \& Ozonoff, S. (2005). Annotation: What do we know about sensory dysfunction in autism? A critical review of the empirical evidence. Journal of Child Psychology and Psychiatry, 46(12), 12551268 .

Schneider, P. (2002). Do school facilities affect academic outcomes? National Clearinghouse for Educational Facilities, USA, November.

Shibata, S., \& Suzuki, N. (2004). Effects of an indoor plant on creative task performance and mood. Scandinavian Journal of Psychology, 45, 373-381.

Singhania, R. (2005). Autism spectrum disorders. The Indian Journal of Pediatrics, 72(4), 343-351.

Strayhorn, J. M., Jr., \& Bickel, D. (2002). Reduction in children's symptoms of attention deficit hyperactivity disorder and oppositional defiant disorder during individual tutoring as compared with classroom instruction. Psychological Reports, 91, 69-80.

Tennessen, C. M., \& Cimprich, B. (1995). Views to nature: Effects on attention. Journal of Environmental Psychology, 15, 77-85.

Thapar, A., van den Bree, M., Fowler, T., Langley, K., \& Whittinger, N. (2006). Predictors of antisocial behaviour in children with attention deficit hyperactivity disorder. European Child and Adolescent Psychiatry, 15, 118-125.

Tufvesson, C. (2007). Concentration difficulties in the school environment-with focus on children with ADHD, Autism and Down's syndrome. PhD-Thesis, Lund University, Sweden.

Wilson, A. (2004). Productivity and green buildings. Environmental Building News, 13(10), 10-15.

Zentall, S. S. (2005). Theory- and evidence-based strategies for children with attentional problems. Psychology in the Schools, 42(8), 821-836. 


\section{Other references}

The Swedish Government Bill 1999/2000, p. 79. From patient to citizen: A national action plan for disability policy.

The Swedish National Agency for Education, The Swedish Education Act, SFS 1985, p. 1100.

The Swedish National Board of Housing, Building and Planning regulations: BFS 1993, p. 57-2006, p. 12 BBR.

The Swedish National Board of Housing, Building and Planning regulations: BFS 2003, p. 19 HIN1.

The Swedish Work Environment Authority: The Work Environment Act, AFS 2000, p. 42.

United Nations' Standard Rules on the Equalisation of Opportunities for Persons with Disabilities; A/RES/ 48/96, 1993.

United Nations' Universal Declaration of Human Rights, 1948. 